\title{
Health impact of intestinal helminth infections among podoconiosis patients
}

\author{
Desalegn Amenu \\ Correspondence: wadadesalegn@gmail.com

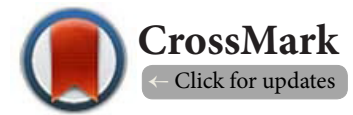 \\ College of Natural and Computational Science, Wollega University, Nekemte, Ethiopia.
}

\begin{abstract}
Intestinal helminth infections are most common diseases of the poor and a potential cause ofanemia in developing countries. Podoconiosis is non-filarial "elephantiasis" of the lower legs in farmers that work on loamy clay soil and is a chronic complication that does not have effective treatment. Soil contact being the mode of transmission of geo-helminths and the cause of podoconiosis, the aim of this paper is to investigate the health impact of helminth infections of podoconiosis patients. On the other hand, the overall prevalence of intestinal geo-helminth infection decreased with increasing clinical stages of podoconiosis, implying that with severe and complicated podoconiosis, the individual would be seriously incapacitated to work on the farm and hence will have a limited contact with soil to be exposed to helminth infections. The study has provided good evidence to justify selective initiation of deworming and iron rich nutrient supplementation to improve the well being of podoconiosis patients under resource poor conditions.
\end{abstract}

Keywords: Podoconiosis, helminths, anemia, hookworm

\section{Review}

\section{Intestinal helminth infections}

Intestinal helminths are common parasitic infectious agents of humans in the world mainly indeveloping countries [21]. More than 2,000 million people are infected by soil transmitted helminths (STH) worldwide, of which more than 300 million suffer from associated severe morbidity. STH infections are widely distributed in tropical and subtropical areas, especially in poor populations (Montresor et al., 2002). Climate is an important determinant factor for transmission of these infections in the tropical and sub tropical areas, with adequate moisture and warm temperature essential for larval development in the soil. Equally important determinants are poverty and inadequate clean water supplies and sanitation. In such condiwtions, soil transmitted helminth species are commonly coendemic. Morbidity and rate of transmission of STH infections are directly related to the number of worms harbored in the host. Intensity of infection is measured by the number of eggs per gram of faeces, generally by the Kato-Katz fecal thick-smear technique [4].

Intestinal parasitism has been widespread in Ethiopia. Parasitic helminthic infections are themost predominant causes of outpatient morbidity in the country [27]. Several studies have indicated that the prevalence of parasitic infectionsis higher at lower altitudes in Ethiopia. In Ethiopia, the coverage of safe drinking water and latrine is very low
(Kumie and Ali, 2005). Poor environmental sanitation and climatic conditions (hot, wet and humid) were reported to favor the persistence of parasite ova in Ethiopia [27].

\section{Anemia and intestinal helminth infections}

Although soil transmitted helminths (STH) do not cause significant mortality when compared with many other parasitic diseases, they do cause substantial morbidity. Infections with STH have a pronounced impact on nutrition, growth, physical fitness, cognitive function and anemiain infants, school-age children and adults. These infections have long term effects and are measured in terms of disease impact statistics, such as disability-adjusted life years (DALYs) [4].

One of the oldest established nutrition and infection relationships is the one that describes how STH nematodes lead to iron deficiency anemia. It has long been established that high intestinal worm burdens with Ascaris lumbricoides, Trichuris trichiura, Ancylostoma duodenale and/or Necator americanus lead to anorexia, decreased food intake and weight loss, decreased nutrient absorption and utilization, and gut pathophysiology. When these conditions occur with extensive parasitosis, the accompanying intestinal blood loss can result in moderate to severe anemia requiring treatment. In most developing countries, STH or gastrointestinal nematode infections are important predictors of anemia and the severity of anemia is proportional to worm burdens [23]. 
Desalegn Amenu, Trends in Bacteriology 2014,

http://www.hoajonline.com/journals/pdf/2057-4711-1-2.pdf

doi: 10.7243/2057-4711-1-2

\section{Hookworm infection}

Human hookworm infection is caused by helminth parasites of species Necator americanus and Ancylostoma duodenale. $N$. americanus is the predominant etiology of human hookworm infection worldwide, whereas $A$. duodenale occurs in more scattered focal environments. This infection is one of the most common chronic infections, and has a prevalence of 740 million cases in areas of rural poverty in the tropics and subtropics [12]. The greatest number of hookworm cases occurs in Asia, followed by sub-Saharan Africa [12]. High hookworm transmission also occurs in southern China, the Indian subcontinent, and the Americas. In all regions, there is a striking relationship between hookworm prevalence and low socioeconomic status. Hookworm's neglected status partly reflects its concentration among the world's poorest 2.7 billion people who live on less than $\$ 2$ a day $[12,20]$.

For many common helminthic infections, including ascariasis, trichuriasis, and schistosomiasis, the intensity of infection usually peaks during childhood and adolescence (Bundy, 1995). Incontrast, there appears to be considerable variation in the age intensity profile of hookworm infection. Although the hookworm burden may be heavy in children, especially those in sub Saharan Africa, the most commonly recognized pattern is a steady rise in the intensity of infection during childhood, with either a peak or a plateau in adulthood [19].The observation that the intensity of hookworm infection increases with age is due to its occupational nature and has led to the suggestion that hookworms can either evade or suppress host immune responses (Loukas and Prociv, 2001).

\section{Pathophysiology and clinical disease of hookworm}

Hookworm infection is acquired by invasion of the infective larval stages through the skin ( $A$. duodenale larvae can also enter through oral method). Following host entry, the larvae undergo ajourney through the vasculature, then the lungs and other tissues, before they enter the gastrointestinal tract and molt twice to become one-centimeter-long adult male and female worms. The worms mate and the female hookworms produce up to 30,000 eggs per day, which exit the host's body in the feces. Because hookworms do not replicate in humans, the morbidity of hookworm is highest among patients that harbor large numbers of adult parasites. Estimates of the intensity of hookworm infection are typically obtained by using quantitative fecal egg counts as a surrogate marker for worm burden. The World Health Organization defines moderate intensity infections as those with 2,000-3, 999 eggs per gram of feces, and heavy intensity infections as those with 4,000 or more eggs per gram [19].

The major hookworm-related injury in humans occurs when the adult parasites cause morbidity in the host by producing intestinal hemorrhage. Because the adult hookworms ingest the blood, rupture the erythrocytes, and degrade the hemoglobin; the disease attributed to hookworm is silent blood loss leading to iron deficiency anemia and protein malnutrition. During the feeding activity of the parasite, capillaries and arterioles are ruptured not only mechanically but also chemically, through the action of hydrolytic enzymes [17]. To ensure blood flow, the adult hookworms release anti clotting agents (Stanssens et al., 1996) there by further increasing loss of blood from the intestine. The extent of iron deficiency anemia induced by hookworms varies with hookworm species. Infection with $A$. duodenale causes greater blood loss ( $0.2 \mathrm{ml}$ blood/day) than does infection with $N$. americanus (0.03 $\mathrm{ml}$ blood/day) [29].

There is a correlation between parasite intensity and host intestinal blood loss. In children, women of reproductive age, and other populations with low iron stores, there is often a correlation between parasite intensity and reductions in host hemoglobin. In children, chronic heavy-intensity infections are associated with growth retardation, as well as intellectual andcognitive impairments; in pregnant women, they are associated with adverse maternal-fetal outcomes [20]. Depending on the status of host iron, a hookworm burden (i.e., the intensity of infection, or number of worms per person) of 40 to 160 worms is associated with hemoglobin levels below $11 \mathrm{~g}$ per deciliter. However, other studies have shown that anemia may occur with a lighter hookworm burden [29].

\section{Hookworm prevention and control strategies}

Public education on the dangers associated with dirt contaminated with human faeces can help reduce the number of cases of hookworm infection. Education programs should highlight the importance of disposing of human faeces in a sanitary way so that it does not contaminate the soil, wearing covered footwear in areas where the disease is endemic and washing hands after using toilet. Therefore, sanitation and footwear are important means of reducing transmission of hookworm. Sanitation measures include the provision of latrines along with training in their use and the appropriate treatment of human waste before use in activities like agriculture [37]. Because of its high transmission potential in areas of poverty and poor sanitation, hookworm infection is difficult for eradication [20]. In countries with less economic development, there is poor functioning of public health services in activities like sanitation, footwear and health education are minimal and therefore, control efforts have shifted to reduce morbidity through mass treatment (also known as "deworming") of affected populations with antihelminthic drugs [5]. The most common control strategies through treatment for hookworm are Benzimidazoles (BZAs), specifically albendazoleand mebendazole. BZAs kill adult worms by binding to the nema-tode's betatubulin and subsequently inhibiting microtubule polymerization within the parasite [4].

\section{Podoconiosis}

Elephantiasis can be filarial or non-filarial in its origin. The filarial elephantiasis also known aslymphatic filariasis is caused by the parasitic filarial worms like Wuchereria bancrofti, 
Brugiamalayi and B. timori, all of which are transmitted by mosquitoes (CDC, 2008). Lymphatic filarias is affects more than 120 million people in over 80 countries worldwide being most prevalent in Africa, India and South Asia, the Pacific, and the Americas. The other form of elephantiasis occurs in the absence of parasitic infection. This non-parasitic form of elephantiasis is known as podoconiosis, and has been reported from many parts of the world; but exists as an endemic disease in geographically circumscribed areas [35].

Podoconiosis (endemic non-filarial elephantiasis) is widely distributed in the world with it shighest prevalence in tropical or sub tropical latitudes. Highland areas of tropical and sub tropical regions are the main distribution foci of the disease. The distribution of the disease inthis area is associated with the presence of irritant red clay soil of volcanic origin. The affected individuals are mainly bare footed farmers that work on red clay soils [35]. Characteristically, the soils are red clay loams, which are slippery and adhere to the skin whenwet. Most cases of podoconiosis have been reported from highlands of tropical Africa, Central America and Northwest India [35]. In Africa it is widely prevalent in countries such as Ethiopia, Kenya, Tanzania, Rwanda and Burundi, all of which are associated with the Rift Valley geological complex $[31,35]$. Common features for affected areas are altitudes above $1250 \mathrm{~m}$, annual rainfall above $1000 \mathrm{~mm}$, average annual temperature of $20^{\circ} \mathrm{C}$, and soils of volcanic origin [35].

The history of podoconiosis is better described in Ethiopia than any where else in the world [10]. In Ethiopia alone, 13 million people ( $18 \%$ of the population) are at risk through exposure to irritant soil. An estimate based on prevalence data from an endemic area in southern Ethiopia suggested that between 500,000 and 1 million people are affected nationwide [13]. The worst part of the disease, besides health complication, is that it affects patients socioeconomically. It has negative impact on economic activity in that it affects the productive age groups in the community. In most cases this disease occurs between the ages 16 and 45 years, the ages most responsible for agricultural and domestic productivity [39].

It was found that about $80 \%$ of all patients and $86.7 \%$ of female patients were involved ineconomic and domestic activities, but worked less than those free of the condition. The time lostand the cost incurred through it is likely to recur day after day because of the chronic nature of the disease [39]. Furthermore, social stigma against people with podoconiosis is a frequently observed situation. Patients are highly discriminated in the society and denied participation in local meetings, churches and mosques, and barred from marriage with unaffected individuals $[\mathbf{8 , 4 4}]$.

\section{Etiology, pathology and genetic predisposition}

The etiology, pathology and clinical features of podoconiosis have been well studied by Price(1990) where he showed that soil borne minerals are the primary causes of the disease. The minerals involved may include silica and alumino-silicate, and they are always found in the volcanic clays in areas where podoconiosis is endemic. These pathogenic soils are characterized by a high proportion of abrasive quartz crystals in the fine silts and of colloidal-size particles in clays. These soil particles are capable of penetrating through the skin of the bare foot. Micro-particles entering through the skin accumulate in different parts of body tissues. Accumulation of the particles is high in those segments of the lymph nodes, into which the lymphatics of the foot and the lower leg drain [33]. Soil particles causing the obstructive lymphopathy have been found in biopsy specimens from the dermis, lymphatic vessels and lymph glands [34].

The clinical state of patients with podoconiosis provides evidence that the condition is an obstructive lymphopathy. Epidemiological surveys indicate an association between the disease and the local soils. As demonstrated by Spooner and Davies (1986), the toxicity of the soil tocultures of macrophages depends on the concentration of soil particles entering the body. Changes are observed in the dermis, lymphatic channels and drainage lymph nodes, with longterm deposition of silica and alumino-silicate thought to result in obstruction leading to lymphedema [35].

Host genetic factors are important determinants of susceptibility to podoconiosis since not all individuals exposed to red clay soils develop podoconiosis [9]. The gene and environment interaction plays a role in development and progression of the disease. Price and Henderson (1978) had observed silicon and aluminium particles within lymph node macrophages of podoconiosis and non-podoconiosis individuals living on irritant soil. And their study suggested that there was abnormal reaction to mineral particles absorbed into the lymphatic system in the body of podoconiosis patients than in nonpodoconiosis individuals. This implied the role of gene as predisposing factor for podoconiosis [32].

The early symptoms in podoconiosis are characterized by skin itching of the forefoot and aburning sensation in the lower leg, particularly the foot. Plantar edema, lymph fluid oozing from the area, increased skin markings and skin papillomas as well as rigid toes are early changes observed in early signs of podoconiosis. In the later stages of disease progression, the symptom of lower leg swelling may be noticed either as soft elephantoid leg or hard and fibrotic type of swelling. The nature of progression of the disease from early to later clinical signs is very dormant and may take few to several years. Therefore, the victim suffers from the disease through out life starting from the onset of the condition $[8,35]$.

\section{Prevention and management of podoconiosis}

Prevention of contact with sticky red clay soils in the genetically vulnerable individuals will prevent the onset of the condition [33]. This can be achieved through use of footwear, education and raising public awareness of the disease within at risk communities and the improvement of farming techniques which protect the population from direct and 
Desalegn Amenu, Trends in Bacteriology 2014,

prolonged skin contact with the offending soil. Management of podoconiosis includes managing the early phase of the disease and the late (established) lymphoedematous presentation of the disease. Successful management depends on the understanding and co-operation of the patient and well informed community [35].

Early podoconiosis can be managed before persistent lymphedema develops (Price, 1983) and this involves educating individuals about the disease and its causes, encouraging shoe wearing at all times, especially when farming or in contact with the characteristic soil and prompt treatment of secondary infections with antibiotics. In podoconiosis endemic areas, sophisticated and expensive management techniques are unavailable and because of this the approach focuses on more practical, low-cost methodologies that are accessible in the resource poor settings of the majority of podoconiosis patients. These simple methods include cleansing, daily moistening of the limb, elevation of the limb to above hip height for prolonged periods to improve venous and lymphatic return and reduce limb size, compression or bandaging, manual lymphatic drainage by superficial massaging and use of appropriate or protective footwear (Fuller, 2005). Management of the established lymphedematous patients in podoconiosis shares many similarities with the management of any lymphedematous diseases like diseases of lymphatic filariasis [42].

\section{Podoconiosis and hookworm Geographical overlap}

Both hookworm and podoconiosis have more or less similar geographical distribution in that they are highly prevalent in tropical and sub-tropical areas of developing world. One reason for the high prevalence of these diseases in these areas is that the majority of the people in the area are bare footed farmers (Price, 1990) who are actively working on the fertile soils of the area. Most of these farmers do not wear protective shoes throughout their life during farming. The fertile soils of tropical and sub-tropical areas conceal causative agents of both diseases. Silica and alumino-silicates, the etiologic agents of podoconiosis, are abundantly found in red clay soils of tropical and sub-tropical highlands [1]. In the same areas where sanitary practices are poor, the soils are infested with eggs and larvae of hookworm and other helminths.

Lack of safe water, latrine and appropriate waste disposal accounts for the highest infestation of eggs and larvae of helminths in the area [14]. The warm and humid climate of tropical and sub-tropical regions is another factor for persistence of parasites in the soil [27]. In any case, the bare footed farmers are the most exposed group of people in the tropical and sub-tropical areas. Therefore, podoconiosis and hookworm could have overlapping distribution [1].

\section{Occupational overlap}

The distribution of podoconiosis and hookworm infections has relationship with occupation. These diseases are commonly observed among farm workers who work on bare foot. Soil is asource of infection for both diseases. Survival of hookworm larvae is favored in damp, sandy or friable environments [1]. Inadequate footwear increases foot trauma, podoconiosis, hookworm and other parasitic infections that enter the bare foot. In order toprevent infections occurring due to skin-soil contact, the primary step is reducing soil contact behavior within risk groups. In relation to podoconiosis, soil particles absorbed through the feet cause the disease [32].

\section{Anemia}

Anemia is defined as a condition where there is less than the normal hemoglobin $(\mathrm{Hb})$ level I the body, which decreases oxygen-carrying capacity. World Health Organization (WHO) definitions for anemia differ by age, sex, and pregnancy status as follows: for children 6 months to 5 years of age anemia is defined as a $\mathrm{Hb}$ level $<11 \mathrm{~g} / \mathrm{dL}$, children $5-11$ years of age $\mathrm{Hb}<11.5 \mathrm{~g} / \mathrm{dL}$, adult males $\mathrm{Hb}<13 \mathrm{~g} / \mathrm{dL}$; non-pregnant females $\mathrm{Hb}<12 \mathrm{~g} / \mathrm{dL}$; pregnant females $\mathrm{Hb}<11 \mathrm{~g} / \mathrm{dL}$ and Severe anemia is defined as $\mathrm{Hb}<7.0 \mathrm{~g} / \mathrm{dL}$ [43]. Anemia affects about 2 billion people worldwide and is a serious public health problem (Roland et al., 2007). The highest prevalence of anemia occurs in the developing world. Anemia is related to reduced work capacity, reduced ability to execute activities of daily living, poor pregnancy outcomes and reduced cognitive function. Assessing the causes of anemia is complex, especially where many different etiologic agents are at play simultaneously, as is the case inmuch of the developing world (Friedman et al., 2005).

Anemia can be caused by different factors. Nutritional deficiencies are regarded as the most important cause of anemia in the world and a major potential contributor to adolescent anemia in sub-Saharan Africa [26]. Iron deficiency is the main source of nutrition related anemia. According to Kriviene and Ragelienè (2006), half of all reasons for anemia are iron deficiency.

Besides specific nutrient deficiencies, general infections and chronic diseases, as well as bloodloss, can cause anemia. The risk of anemia increases when individuals are exposed to malaria and helminth infections. There are also many other rarer causes of anemia, the most common being genetic disorders such as thalassemia. Malaria, especially due to the protozoan Plasmodium falciparum, causes anemia by rupturing red blood cells and by suppressing the production of new red blood cells [25]. Malaria does not, however,cause iron deficiency, because much of the iron in hemoglobin released from the ruptured cellstays in the body. Helminths such as hookworms can cause blood loss and therefore iron loss.Adult hookworms attach themselves to the gut wall, where the mature larvae and adult worms ingest both the gut wall cells and blood. Hookworms change feeding sites every 4-6 hours and during feeding secrete an anticoagulant, resulting in secondary blood loss from the damaged gutwall after the worms have 
stopped feeding. The number of adult hookworms and the fecal eggcount, which is an indirect estimate of the number of worms, are strongly correlated with the amount of blood lost which, if chronic, can result in iron deficiency anemia. The nematode Trichuris trichiura can cause anemia when the worm burden is heavy. Heavy infections alsocause inflammation and dysentery, which in turn can cause further blood loss [24].

Anemia adversely affects people worldwide and occurs when there is inadequate number of red blood cells or inadequate amount of hemoglobin for the body to function properly. Hemoglobin is a protein in red blood cells that carries oxygen to the brain, muscular system, immune system, and other parts of the body. Without adequate oxygen, the physical and mental capacities of individuals are reduced [28]. Strong evidence links anemia to health and development problems. Anemia in pregnant women results in lower birth weight babies who have a higher risk of death. Iron deficiency with or without anemia reduces work productivity in adults and limits cognitive development in children, thus limiting their achievement in school and ultimately reducing investment benefits in education. In addition, iron-deficiency leads to impaired gastrointestinal functions. Iron deficiency anemia also has adverse effects on the immune system because it results in reduced resistance to infections [38].

In Ethiopia, there is a high prevalence of anemia. However, the magnitude and importance ofiron deficiency anemia as a public health problem is still under investigation because in several developing countries the intake of iron from diet is more than adequate. For example, in parts of Ethiopia, the daily intake of iron is estimated to be between 180 and $500 \mathrm{mg} /$ day which is 10-20times the suggested daily requirement. This presumed high intake is attributed to consumption of a staple cereal, teff (Eragrostis teff) ( $90 \mathrm{mg}$ of iron per $100 \mathrm{~g}$ of teff), and partly due to its contamination with iron-rich clay soil [41]. Inspite of the high intake of iron in teff-consuming communities, there is high prevalence of anemia. Therefore, the cause of iron deficiency in Ethiopia may not be the inade-quate dietary intake of iron i.e., other etiologic factors like iron malabsorption and iron loss might play a role iniron deficiency anemia. In such communities with an already high intake of iron, the conventional supplementation of iron might not be an effective method of intervention or might even be harmful as iron overload in the body damages organs such as liver and heart (Kohgo et al., 2008). Therefore, all important risk factors have to be identified and their role in causing anemia evaluated [2].

The aim of this paper is to investigate the co-existence of two chronically debilitating diseases, podoconiosis and helminth infections particularly hookworm, in a population of podo coniosis patients. No studies in Ethiopia have investigated the co-occurrence of intestinal helminth infection on podoconiosis patients. Podoconiosis and hookworm have two things in common: they enter the human body through the skin and they chronically affect patients. Low socioeconomic conditions, poor hygienic habits, lack of sanitation and lack of health education are related to the wider prevalence of hookworm and other intestinal helminthic infections (Muznebin et al., 2007).

\section{Competing interests}

The author declares that he has no competing interests.

\section{Publication history}

Editor: Triveni Krishnan, National Institute of Cholera and Enteric Diseases India.

EIC: Tobiasaleciomattei, Ohio State University, USA.

Received: 24-Feb-2014 Revised: 28-Apr-2014

Accepted: 27-Jun-2014 Published: 02-Jul-2014

\section{References}

1. Abrahams PW. Soils: their implications to human health. Sci Total Environ. 2002; 291:1-32. | Article | PubMed

2. Adish AA, Esrey SA, Gyorkos TW and Johns T. Risk factors for iron deficiency anaemia in preschool children in northern Ethiopia. Public Health Nutr. 1999; 2:243-52. I Article I PubMed

3. Bethony J, Chen J, Lin S, Xiao S, Zhan B, Li S, Xue H, Xing F, Humphries D, Yan W, Chen G, Foster V, Hawdon JM and Hotez PJ. Emerging patterns of hookworm infection: influence of aging on the intensity of Necator infection in Hainan Province, People's Republic of China. Clin Infect Dis. 2002; 35:1336-44. | Article | PubMed

4. Bethony J, Brooker S, Albonico M, Geiger SM, Loukas A, Diemert D and Hotez PJ. Soil-transmitted helminth infections: ascariasis, trichuriasis, and hookworm. Lancet. 2006; 367:1521-32. | Article | PubMed

5. Brooker S, Bethony J and Hotez PJ. Human hookworm infection in the 21st century. Adv Parasitol. 2004; 58:197-288. | Article I PubMed Abstract | PubMed Full Text

6. Brooker. S, Hotez, P. J and Bundy D.A.P.. Hookworm-related anemia among pregnant women: A systematic review. PLoSNegl. Trop. 2008. I Article

7. Davey G, Venn A, Belete H, Berhane $Y$ and Britton J. Wheeze, allergic sensitization and geohelminth infection in Butajira, Ethiopia. Clin Exp Allergy. 2005; 35:301-7. I Article I PubMed

8. Davey G, Gebrehanna E, Adeyemo A, Rotimi C, Newport M and Desta K. Podoconiosis: a tropical model for gene-environment interactions? Trans R Soc Trop Med Hyg. 2007; 101:91-6. | Article I PubMed

9. Davey G, Tekola F and Newport MJ. Podoconiosis: non-infectious geochemical elephantiasis. Trans R Soc Trop Med Hyg. 2007; 101:117580. | Article | PubMed

10. Davey, G. Podoconiosis: let Ethiopia lead the way. Ethiop. J. Health. Dev. 2008; 22:1-2. I Pdf

11. Davey $G$ and Burridge E. Community-based control of a neglected tropical disease: the mossy foot treatment and prevention association. PLoS Negl Trop Dis. 2009; 3:e424. | Article | PubMed Abstract | PubMed Full Text

12. de Silva NR, Brooker S, Hotez PJ, Montresor A, Engels D and Savioli L. Soiltransmitted helminth infections: updating the global picture. Trends Parasitol. 2003; 19:547-51. I Article I PubMed

13. Desta, K, Ashine, M and Davey, G. Prevalence of podoconiosis (endemic non-filarial elephantiasis) in Wolaita, Southern Ethiopia. Trop. Doct. 2008; 32:217- 220.

14. Ekpo UF, Odoemene SN, Mafiana CF and Sam-Wobo SO. Helminthiasis and hygiene conditions of schools in Ikenne, Ogun State, Nigeria. PLoS Negl Trop Dis. 2008; 2:e146. | Article | PubMed Abstract | PubMed Full $\underline{\text { Text }}$

15. Fuller LC. Podoconiosis: endemic nonfilarial elephantiasis. Curr Opin Infect Dis. 2005; 18:119-22. | Article | PubMed

16. Horton J. Human gastrointestinal helminth infections: are they now neglected diseases? Trends Parasitol. 2003; 19:527-31. | Article | PubMed 
Desalegn Amenu, Trends in Bacteriology 2014,

17. Hotez PJ, Hawdon JM, Cappello M, Jones BF and Pritchard DI. Molecular pathobiology of hookworm infection. Infect Agents Dis. 1995; 4:71-5. | PubMed

18. Hotez PJ, de Silva N, Brooker S and Bethony J. Soil transmitted helminth infections: The nature, causes and burden of the condition. Maryland Nation.Inst. Health. 2003; 3: 1-79.

19. Hotez, PJ, Brooker, S., Bethony, J., Bottazzi, M.E. and Loukas, A. Current concepts: Hookworm infection. N. Engl. J. Med. 2004; 351:799-807. | Article

20. Hotez PJ, Bethony J, Bottazzi ME, Brooker S and Buss P. Hookworm: "the great infection of mankind". PLoS Med. 2005; 2:e67. | Article | PubMed Abstract | PubMed Full Text

21. Hotez P. Hookworm and poverty. Ann N Y Acad Sci. 2008; 1136:38-44. Article | PubMed

22. Hotez PJ, Brindley PJ, Bethony JM, King CH, Pearce EJ and Jacobson J. Helminth infections: the great neglected tropical diseases. J Clin Invest. 2008; 118:1311-21. | Article | PubMed Abstract | PubMed Full Text

23. Koski1 K G. and Scott M E. Gastrointestinal nematodes, trace elements, and immunity. J. Trace Elem. Exp. Med. 2003; 16:237-251. | Article

24. Koukounari A, Estambale BB, Njagi JK, Cundill B, Ajanga A, Crudder C, Otido J, Jukes MC, Clarke SE and Brooker S. Relationships between anaemia and parasitic infections in Kenyan schoolchildren: a Bayesian hierarchical modelling approach. Int J Parasitol. 2008; 38:1663-71. | Article | PubMed Abstract | PubMed Full Text

25. Krivienè, I and Ragelienè L. The prevalence of anemia among schoolchildren in Šiauliai region of Lithuania. Acta Med. Lituan. 2006; 13:56-59. I Pdf

26. Leenstra T, Kariuki SK, Kurtis JD, Oloo AJ, Kager PA and ter Kuile FO. Prevalence and severity of anemia and iron deficiency: cross-sectional studies in adolescent schoolgirls in western Kenya. Eur J Clin Nutr. 2004; 58:681-91. | Article | PubMed

27. Mengistu A, Gebre-Selassie S and Kassa T. Prevalence of intestinal parasitic infections among urban dwellers in southwest Ethiopia. Ethiop.J.Health. Dev. 2007; 21:12-17. | Article

28. MOST, USAID Micronutrient Program. A Strategic Approach to Anemia Control Programs. Arlington, Virginia, USA. 2004.

29. Olsen A, Magnussen P, Ouma JH, Andreassen J and Friis H. The contribution of hookworm and other parasitic infections to haemoglobin and iron status among children and adults in western Kenya. Trans R Soc Trop Med Hyg. 1998; 92:643-9. I Article I PubMed

30. Pawlowski ZS, Schad GA and Stott GJ. Hookworm infection and anemia approaches to prevention and control. WHO, Geneva. 1991.

31. Price EW. The association of endemic elephantiasis of the lower legs in East Africa with soil derived from volcanic rocks. Trans $R$ Soc Trop Med Hyg. 1976; 70:288-95. I Article I PubMed

32. Price EW and Henderson WJ. The elemental content of lymphatic tissues of barefooted people in Ethiopia, with reference to endemic elephantiasis of the lower legs. Trans R Soc Trop Med Hyg. 1978; 72:1326. | Article | PubMed

33. Price EW. Endemic elephantiasis: early signs and symptoms, and control. Ethiop Med J. 1983; 21:243-53. I PubMed

34. Price EW and Bailey D. Environmental factors in the etiology of endemic elephantiasis of the lower legs in tropical Africa. Trop Geogr Med. 1984; 36:1-5. I PubMed

35. Price, E.W. Podoconiosis.Non-filarial elephantiasis. Oxford University Press, Oxford. 1990.

36. Spooner NT and Davies JE. The possible role of soil particles in the aetiology of non-filarial (endemic) elephantiasis: a macrophage cytotoxicity assay. Trans R Soc Trop Med Hyg. 1986; 80:222-5. | Article | PubMed

37. Stoltzfus RJ, Dreyfuss ML, Chwaya HM and Albonico M. Hookworm control as a strategy to prevent iron deficiency. Nutr Rev. 1997; 55:22332. | Article | PubMed

38. Stoltzfus RJ. Iron-deficiency anemia: reexamining the nature and magnitude of the public health problem. Summary: implications for research and programs. J Nutr. 2001; 131:697S-700S; discussion 700S-701S. | Article | PubMed

39. Tekola F, Mariam DH and Davey G. Economic costs of endemic nonfilarial elephantiasis in Wolaita Zone, Ethiopia. Trop Med Int Health. 2006; 11:1136-44. | Article | PubMed

40. Tekola F, Ayele Z, Mariam DH, Fuller C and Davey G. Development and testing of a de novo clinical staging system for podoconiosis (endemic non-filarial elephantiasis). Trop Med Int Health. 2008; 13:1277-83. | Article | PubMed Abstract | PubMed Full Text

41. Umeta M, Haidar J, Demissie T, Akalu G and Ayana G. Iron deficiency anemia among women of reproductive age in nine administrative regions of Ethiopia. Ethiop. J. Health. Dev. 2008; 22:252-258.

42. Vaqas B and Ryan TJ. Lymphoedema: Pathophysiology and management in resource-poor settings - relevance for lymphatic filariasis control programmes. Filaria J. 2003; 2:4. | Article | PubMed Abstract | PubMed Full Text

43. WHO .Report of the global partners meeting on neglected tropical diseases, Geneva 1. 2007.

44. Yakob B, Deribe K and Davey G. High levels of misconceptions and stigma in a community highly endemic for podoconiosis in southern Ethiopia. Trans R Soc Trop Med Hyg. 2008; 102:439-44. | Article | PubMed

\section{Citation:}

Amenu D. Health impact of intestinal helminthinfections among podoconiosis patients. Trends Bacteriol. 2014; 1:2. http://dx.doi.org/10.7243/2057-4711-1-2 